\title{
ANALISIS HUBUNGAN BALOK KOLOM BETON BERTULANG PROYEK PEMBANGUNAN GEDUNG DPRD-BALAI KOTA DKI JAKARTA
}

\author{
Agus Setiawan \\ Civil Engineering Department, Faculty of Engineering, Binus University \\ Jl. K.H. Syahdan No. 9, Palmerah, Jakarta Barat 11480 \\ agustinusset@yahoo.com
}

\begin{abstract}
In terms of structural design of reinforced concrete buildings for earthquake-resistant, the beamcolumn joint is a critical area that needs to be accurately designed properly so that the area is able to dissipate energy in the event of an earthquake. The ability of beam-column joint to deform in the inelastic region provides a structure that has a good ductility, so as to minimize the damage caused by earthquake shaking. This study aims to analyze the design of beam-column connection at the Parliament Building-City Hall of Jakarta. The analysis performed refers to the "Tata Cara Perhitungan Struktur Beton Untuk Bangunan Gedung", SNI 03-2847-2002. The analysis results shows that the terms of detailing in the field implementation have not been fulfilled properly.
\end{abstract}

Keywords: beam-column joint, dissipate, inelastic

\begin{abstract}
ABSTRAK
Dalam perencanaan struktur bangunan gedung beton bertulang yang tahan gempa, daerah hubungan balok-kolom merupakan daerah kritis yang perlu didesain benar-benar akurat sehingga mampu mendisipasi energi dengan baik pada saat terjadi gempa. Kemampuan hubungan balok-kolom untuk berdeformasi pada daerah inelastik memberikan struktur dengan daktilitas baik, sehingga mampu meminimalisasi kerusakan yang terjadi akibat goyangan gempa bumi. Penelitian ini bertujuan untuk menganalisis desain hubungan balok-kolom pada Gedung DPRD-Balaikota DKI Jakarta, mengacu pada Tata Cara Perhitungan Struktur Beton untuk Bangunan Gedung, SNI 03-2847-2002. Hasil analisis menyatakan bahwa syarat detailing belum dipenuhi secara benar dalam pelaksanaan di lapangan.
\end{abstract}

Kata kunci: hubungan balok kolom, disipasi, inelastik 


\section{PENDAHULUAN}

Daerah hubungan balok-kolom merupakan daerah kritis pada suatu struktur rangka beton bertulang, yang harus didesain secara khusus untuk berdeformasi inelastik pada saat terjadi gempa kuat. Sebagai akibat yang timbul dari momen kolom di atas dan di sebelah bawahnya, serta momenmomen dari balok pada saat memikul beban gempa, daerah hubungan balok-kolom akan mengalami gaya geser horizontal dan vertikal yang besar. Gaya geser yang timbul ini besarnya akan menjadi beberapa kali lipat lebih tinggi daripada gaya geser yang timbul pada balok dan kolom yang terhubung. Akibatnya apabila daerah hubungan balok-kolom tidak didesain dengan benar, akan menimbulkan keruntuhan geser yang bersifat getas dan membahayakan pengguna bangunan.

Guna mendapatkan suatu struktur bangunan yang aman dan tahan terhadap bencana, terutama akibat gempa bumi, struktur harus didesain sedemikian rupa mematuhi kaidah atau aturan konstruksi yang baku. Dalam hal struktur beton bertulang, seluruh bangunan gedung di Indonesia harus didesain mengikuti "Tata Cara Perhitungan Struktur Beton Untuk Bangunan Gedung", SNI 03-2847-2002 (Badan Standarisasi Nasional, 2002). Dalam standar tersebut diatur mengenai dasar-dasar analisis dan perencanaan suatu struktur bangunan beton bertulang, dan dalam pasal 23 diatur mengenai ketentuan khusus untuk perencanaan gempa.

Penelitian ini bertujuan untuk menganalisis hubungan balok-kolom yang terdapat pada proyek pembangunan Gedung DPRD-Balaikota DKI Jakarta (Gambar 1). Penelitian ini hanya dibatasi untuk pemeriksaan daerah hubungan balok-kolom beserta tulangan confinement pada daerah hubungan tersebut. Selanjutnya akan dibandingkan antara kondisi nyata yang terpasang di lapangan dengan perhitungan eksak sesuai standar yang berlaku, dalam hal ini mengacu pada SNI 03-2847-2002, mengenai "Tata Cara Perhitungan Struktur Beton Untuk Bangunan Gedung"

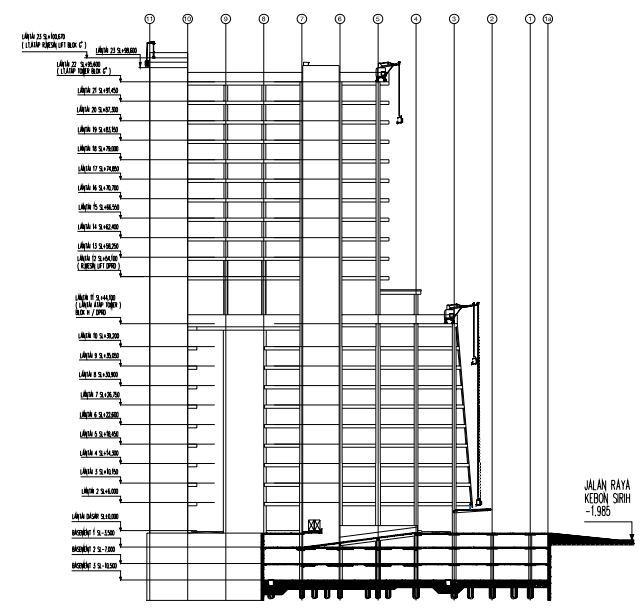

Gambar 1. Potongan tampak samping kanan Gedung DPRD - Balaikota DKI Jakarta.

\section{METODE}

Sebagai kaidah baku dalam perencanaan struktur beton bertulang di Indonesia, SNI 03-28472002 juga memuat secara khusus tata cara perhitungan struktur beton tahan gempa. Pasal 23 dalam SNI 03-2847-2002 memuat secara lengkap peraturan desain struktur beton tahan gempa. Dalam pasal 23.5 dijelaskan pula tata cara untuk melakukan desain pada suatu hubungan balok kolom. 
Beberapa ketentuan dalam perencanaan hubungan balok-kolom dijelaskan dalam pasal 23.5 SNI 03-2847-2002 sebagai berikut: (1) gaya-gaya pada tulangan longitudinal balok di muka hubungan balok-kolom harus ditentukan dengan menganggap bahwa tegangan pada tulangan tarik lentur adalah 1,25 kali tegangan leleh tulangan $\left(1,25 \times f_{y}\right) ;(2)$ kuat hubungan balok-kolom harus direncanakan menggunakan faktor reduksi kekuatan sebesar 0,8 ; (3) apabila tulangan longitudinal balok diteruskan hingga melewati hubungan balok-kolom, dimensi kolom dalam arah paralel terhadap tulangan longitudinal balok tidak boleh kurang daripada 20 kali diameter tulangan longitudinal terbesar balok untuk beton normal, dan tidak kurang dari 26 kali diameter tulangan longitudinal untuk beton ringan.

Dalam hal perencanaan kuat geser, kuat geser nominal hubungan balok-kolom tidak boleh diambil lebih besar daripada ketentuan berikut: (1) untuk hubungan balok-kolom yang terkekang pada keempat sisinya: $1,7 \sqrt{ } f{ }^{\prime} \cdot A_{j}$; (2) untuk hubungan yang terkekang pada ketiga sisinya atau dua sisi yang berlawanan: $1,25 \sqrt{ } f{ }^{\prime} \cdot A_{j}$; (3) untuk hubungan lainnya: $1,0 \sqrt{ } f{ }^{\prime}{ }_{c} \cdot A_{j}$. Panduan menentukan luas efektif hubungan balok-kolom, $A_{j}$, ditunjukkan dalam Gambar 2.

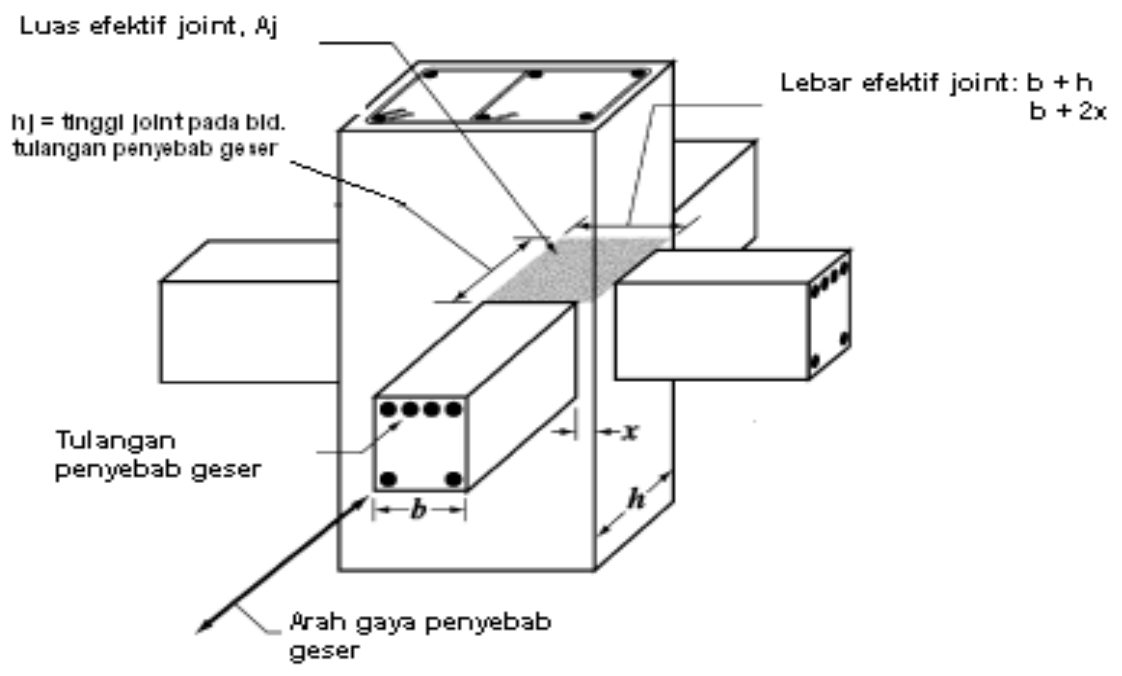

Gambar 2. Luas efektif hubungan balok-kolom.

Gaya geser terfaktor yang bekerja pada hubungan balok-kolom, $V_{u}$, dihitung sebagai berikut (Nawy, 2005):

$$
\begin{aligned}
V_{u} & =T_{1}+C_{2}-V_{\text {kolom }} \\
& =T_{1}+T_{2}-V_{\text {kolom }}
\end{aligned}
$$

dengan

$T_{1} \quad$ adalah gaya tarik pada baja tulangan di balok akibat momen negatif

$T_{2} \quad$ adalah gaya tarik pada baja tulangan di balok akibat momen positif

$C_{2} \quad$ adalah gaya tekan beton akibat momen positif

$V_{\text {kolom }}$ adalah gaya geser pada kolom di sisi atas dan bawah hubungan balok-kolom

Tulangan transversal pada hubungan balok-kolom diperlukan untuk memberikan kekangan yang cukup pada beton, sehingga mampu menunjukkan perilaku yang daktail dan tetap dapat memikul beban vertikal akibat gravitasi meskipun telah terjadi pengelupasan pada selimut betonnya. Luas total tulangan transversal tertutup persegi tidak boleh kurang daripada (Hassoun \& Manaseer, 2005):

$$
A_{s h}=0,09 \cdot s \cdot h_{c} \frac{f^{\prime}{ }_{c}}{f_{y}}
$$




$$
A_{s h} \quad=0,3 \cdot s \cdot h_{c}\left(\frac{A_{g}}{A_{c h}}-1\right) \frac{f^{\prime}{ }_{c}}{f_{y}}
$$

dengan

$A_{\text {sh }} \quad$ adalah luas tulangan transversal yang disyaratkan

$s \quad$ adalah jarak antar tulangan transversal

$h_{c} \quad$ adalah lebar inti kolom yang diukur dari as tulangan longitudinal kolom

$A_{g} \quad$ adalah luas penampang kolom

$A_{c h} \quad$ adalah luas inti penampang kolom

Untuk suatu hubungan balok-kolom dengan ukuran lebar balok sekurang-kurangnya adalah tiga perempat dari lebar kolom, nilai-nilai dalam persamaan (2) dan (3) dapat direduksi sebesar 50\%. Tulangan transversal yang diperlukan harus dipasang sepanjang $l_{0}$ dari setiap muka hubungan balokkolom, dengan panjang $l_{\mathrm{o}}$ ditentukan tidak kurang daripada tinggi penampang komponen struktur pada muka hubungan balok-kolom atau seperenam bentang bersih komponen struktur atau tidak kurang dari $500 \mathrm{~mm}$.

\section{HASIL DAN PEMBAHASAN}

\section{Spesifikasi Balok dan Kolom}

Spesifikasi balok dan kolom yang dianalisis ditampilkan dalam Tabel 1 dan Tabel 2 berikut. Mutu beton balok yang digunakan adalah 24,9 MPa, sedangkan untuk kolom digunakan mutu beton 33,2 MPa.

Tabel 1

Spesifikasi Balok

\begin{tabular}{|l|c|c|c|}
\hline Posisi & Tumpuan & Lapangan & Tumpuan \\
\hline Dimensi & \multicolumn{3}{|c|}{ 350 x 700 } \\
\hline Atas & 8 D 25 & 3 D 25 & 8 D 25 \\
\hline Bawah & 5 D 25 & 5 D 25 & 5 D 25 \\
\hline Sengkang & D10 - 100 & D10 - 150 & D10 - 100 \\
\hline
\end{tabular}

Tabel 2

Spesifikasi Kolom

\begin{tabular}{|l|c|c|c|}
\hline Posisi & Tumpuan & Lapangan & Tumpuan \\
\hline Dimensi & \multicolumn{3}{|c|}{$900 \times 900$} \\
\hline Tulangan utama & \multicolumn{3}{|c|}{$48 \mathrm{D} 25$} \\
\hline Sengkang & 2D10 - 100 & 2D10 - 200 & 2D10 - 100 \\
\hline Pengekang arah x & 2D10 - 100 & 2D10 - 200 & 2D10 - 100 \\
\hline Pengekang arah y & 2D10 - 100 & 2D10 - 200 & 2D10 - 100 \\
\hline
\end{tabular}

Langkah-langkah perhitungan analisis joint kolom balok adalah sebagai berikut:

\section{Menghitung Probable Moment Balok $\left(M_{p r}\right)$}

$$
\begin{array}{ll}
f_{\mathrm{y}} & =400 \mathrm{MPa} \\
f^{\prime} & =24,9 \mathrm{MPa}
\end{array}
$$




$$
\begin{array}{ll}
b & =350 \mathrm{~mm} \\
h & =700 \mathrm{~mm} \\
d & =h-50=650 \mathrm{~mm} \\
A_{s} & =8 \times 490=3920 \mathrm{~mm}^{2} \\
A_{s}^{\prime} & =5 \times 490=2450 \mathrm{~mm}^{2} \\
h_{1}=h_{2} & =4,15 \mathrm{~m}
\end{array}
$$

Untuk $M_{p r}{ }^{-}$

$$
\begin{array}{ll}
T_{1} & =1,25 \times 3920 \times 400 \quad=1.960 \mathrm{kN} \\
a & =1.960 .000 /(0.85 \times 24,9 \times 350)=265,06 \mathrm{~mm} \\
M_{p r}{ }^{-} & =T_{1}(d-a / 2)=1.960 .000(650-265,06 / 2) \\
& =1.016,05 \mathrm{kN} \cdot \mathrm{m}
\end{array}
$$

Untuk $M_{p r}^{+}$

$$
\begin{aligned}
T_{2} & =1,25 \times 2450 \times 400=1.225 \mathrm{kN} \\
a & =1.225 .000 /(0.85 \times 24,9 \times 350)=165,37 \mathrm{~mm} \\
M_{p r}{ }^{+} & =T_{2}(d-a / 2)=1.225 .000(650-165,37 / 2) \\
& =694,96 \mathrm{kN} \cdot \mathrm{m}
\end{aligned}
$$

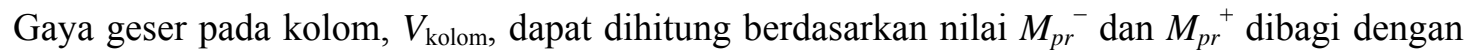
setengah tinggi kolom atas $\left(h_{1}\right)$ ditambah setengah tinggi kolom bawah $\left(h_{2}\right)$. Jika dituliskan dalam bentuk persamaan adalah:

$$
V_{\text {kolom }}=\frac{M_{p r}{ }^{+}+M_{p r}{ }^{-}}{\frac{h_{1}}{2}+\frac{h_{2}}{2}}=\frac{1.016,05+694,96}{\frac{4,15}{2}+\frac{4,15}{2}}=412,29 \mathrm{kN}
$$

Gaya geser terfaktor yang timbul pada hubungan balok-kolom dapat dihitung dengan menggunakan persamaan $V_{u} \quad=T_{1}+T_{2}-V_{\text {kolom, yaitu: }}$

$$
V_{\mathrm{u}} \quad=1.960+1.225-412,29=2.772,71 \mathrm{kN}
$$

Nilai ini tidak boleh lebih besar daripada $\phi V_{n}$, di mana $V_{n}$ adalah kuat geser nominal hubungan balok kolom dan $f$ adalah faktor reduksi kekuatan hubungan balok-kolom yang diambil sebesar 0,8 . Nilai $V n$ dapat dihitung sebagai berikut:

$$
\begin{array}{ll}
V_{n} & =1,7 \sqrt{ } f^{\prime} \cdot A_{j}=1,7 \times \sqrt{ } 33,2 \times(900 \times 900)=7.934,20 \mathrm{kN} \\
\phi V_{n} & =0,8 \times 7.934,20=6.347,36 \mathrm{kN}>V_{u}(=2.772,71 \mathrm{kN})
\end{array}
$$

Jadi, kuat geser hubungan balok kolom sudah mencukupi.

$$
\begin{aligned}
& \text { Menghitung Tulangan Confinement Kolom pada Joint Balok Kolom } \\
& \begin{aligned}
f_{\mathrm{y}} & =400 \mathrm{MPa} \\
f_{\mathrm{c}}^{\prime} & =33,2 \mathrm{MPa} \\
b & =900 \mathrm{~mm} \\
h & =900 \mathrm{~mm} \\
d_{s} & =50 \mathrm{~mm} \\
d_{b} & =25 \mathrm{~mm} \\
d & =h-d_{s}=850 \mathrm{~mm} \\
h_{c} & =h-2\left(d_{s}-d_{b} / 2\right) \\
& =775 \mathrm{~mm}
\end{aligned}
\end{aligned}
$$

Luas total tulangan transversal tertutup persegi tidak boleh kurang dari: 


$$
\begin{aligned}
A_{s h} & =0,09 \cdot s \cdot h_{c} \frac{f^{\prime}{ }_{c}}{f_{y}} \\
A_{s \grave{h}} & =0,3 \cdot s \cdot h_{c}\left(\frac{A_{g}}{A_{c h}}-1\right) \frac{f^{\prime}{ }_{c}}{f_{y}}
\end{aligned}
$$

Dengan mensubstitusikan variabel-variabel yang telah diketahui, diperoleh:

$$
\frac{A_{s h}}{s}=\frac{0,09 \times 775 \times 33,2}{400}=5,79 \mathrm{~mm}^{2} / \mathrm{mm}
$$

dan

$$
\frac{A_{s h}}{s}=\frac{0,3 \times 775 \times 33,2}{400}\left(\frac{900 \times 900}{775 \times 775}-1\right)=6,73 \mathrm{~mm}^{2} / \mathrm{mm}
$$

Sesuai SNI 03-2847-2002 pasal 23.4.4.(2) disyaratkan bahwa tulangan transversal diletakkan dengan spasi tidak lebih dari: (1) 0,25 kali dimensi terkecil struktur, yaitu $0,25 \times 900=225 \mathrm{~mm}$; (2) 6 kali diameter tulangan longitudinal, yaitu $6 d_{b}=6 \times 25=150 \mathrm{~mm}$; (3)

$$
s_{x}=100+\frac{350-h_{x}}{3},
$$

dengan $h_{x}$ dapat diambil sebesar $1 / 3$ kali dimensi inti kolom, atau $1 / 3 \times 775=258,3 \mathrm{~mm}$, sehingga $s_{x}=$ $100+(350-258,3) / 3=130,56 \mathrm{~mm}$. Disyaratkan bahwa nilai $s_{x}$ tidak lebih besar dari $150 \mathrm{~mm}$ dan tidak perlu lebih kecil dari $100 \mathrm{~mm}$.

Dari ketiga syarat tersebut, dapat diambil spasi tulangan transversal adalah $100 \mathrm{~mm}$, hal mana sudah sesuai dengan kondisi yang terpasang di lapangan. Selanjutnya adalah menghitung luas tulangan transversal yang diperlukan berdasarkan nilai $A_{s h} / s$ dan $s$ yang telah diperoleh sebelumnya. Nilai $A_{s h} / s$ terbesar adalah $6,73 \mathrm{~mm}^{2} / \mathrm{mm}$, dan dengan nilai $s=200 \mathrm{~mm}$, diperoleh nilai luas tulangan transversal yang diperlukan sebesar $6,73 \times 100=673 \mathrm{~mm}^{2}$. Misal digunakan D10, jumlah tulangan yang digunakan adalah:

$$
\sum D_{10}=\frac{A_{s h}}{A_{D 10}}=\frac{673}{0,25 \times \pi \times 10^{2}}=8,57 \text { (dibutuhkan } 9 \text { leg D10-100 atau 4,5D10-100) }
$$

Dari hasil perhitungan dibutuhkan 4,5D10-100, dan pada proyek ini sengkang yang terpasang 2D10100.

Tulangan transversal harus dipasang sepanjang $l_{0}$ dari setiap muka hubungan balok-kolom dan juga sepanjang $l_{0}$ pada kedua sisi dari setiap penampang yang berpotensi membentuk leleh lentur akibat deformasi lateral inelastis struktur rangka (SNI 03-2847-2002, pasal 23.4.4.(4)). Panjang $l_{0}$ ditentukan tidak kurang dari: (1) tinggi penampang komponen struktur, yaitu $=900 \mathrm{~mm}$; (2) $1 / 6 \mathrm{kali}$ bentang bersih komponen struktur, yaitu $1 / 6 \times 7100=1183,3 \mathrm{~mm}$; (3) $500 \mathrm{~mm}$. Dari ketiga syarat tersebut, harus diambil nilai terbesar yaitu $1183,3 \mathrm{~mm}$. Sedangkan pada kondisi aktual di lapangan, tulangan transversal terpasang sepanjang 0,25 kali tinggi kolom, yaitu $=0,25 \times 4150=1037,5 \mathrm{~mm}$ dari muka hubungan balok-kolom.

\section{PENUTUP}

Dari hasil analisis yang telah dilakukan dapat diambil beberapa simpulan: (1) ukuran kolom $\left(900 \times 900 \mathrm{~mm}^{2}\right)$ dan balok $\left(350 \times 700 \mathrm{~mm}^{2}\right)$ sudah mencukupi untuk memikul gaya geser yang 
terjadi pada hubungan balok-kolom pada saat terjadi gempa; (2) kebutuhan tulangan geser/transversal ternyata tidak dipenuhi dengan baik sesuai dengan hasil analisis, kebutuhan tulangan transversal adalah 4,5D10-100 namun hanya terpasang 2D10-100; (3) tulangan transversal harus dipasang sepanjang $l_{0}$, yaitu sebesar $1183,3 \mathrm{~mm}$, namun pada kenyataannya hanya terpasang sepanjang 1037,5

$\mathrm{mm}$; (4) dari tinjauan hubungan balok-kolom ini ternyata aturan detailing sebagai suatu Struktur Rangka Pemikul Momen Khusus tidak terpenuhi.

\section{DAFTAR PUSTAKA}

Badan Standarisasi Nasional. (2002). Tata Cara Perhitungan Struktur Beton, SNI 03-28467-2002. Bandung: Departemen Permukiman dan Prasarana Wilayah.

Hassoun, M.N., Manaseer A.A. (2005). Structure Concrete Theory and Design. Canada: John Wiley \& Sons.

Nawy, E. G. (2005). Reinforced Concrete a Fundamental Approach. New Jersey: Pearson Education. 